\title{
利用电子顺磁共振方法研究沉积盆 地源岩有机质热演化*
}

\author{
邱楠生 \\ 汪集晹周礼成 \\ (石油大学地球科学系, 北京 102200) \\ (中国科学院地质研究所, 北京 100029) \\ 张启明陈贵云蔡世祥
}

(南海西部石油公司科学研究院, 湛江. 254057)

关键词电子顺磁共振 (EPR) 自由基 有机质成熟度 古热流

\section{1 实验方法和原理}

利用电子顺磁共振技术研究沉积盆地有机质,主要基于其自由基的变化. 自由基在干酪 根演化过程中的变化及由此引起的电子顺磁共振谱线特征的变化, 是我们用电子顺磁共振研 究有机质热演化的基础. 由干酪根自由基的形成过程可知, 自由基的数目 (浓度) 与受热温度 有关, 随干酪根在热成熟过程中的不断裂解, 失去烷基链, 自由基浓度也就不断增加; 除此以 外, 干酪根结构中杂原子 ( $O, N, S$ 等) 键随演化过程的断裂也会形成自由基. 因而可用电子 顺磁共振方法 (基于自由基浓度的变化)来研究烃源岩的成熟度和盆地的热历史.

实验在 Varian 电子顺磁共振波谱仪上进行, 实验条件为: 中心磁场 $0.3248 \mathrm{~T}$, 微波功 率 $1 \mathrm{~mW}$, 磁场频率 $9.12 \mathrm{GHz}$; 时间常数 $0.0064 \mathrm{~s}$, 扫描速度 $4 \mathrm{~min}$, 扫宽 $0.005 \mathrm{~T}$

\section{2 样品}

27 个样品来自某新生代盆地 (为快速沉降和沉积的环境) 同一凹陷内相邻的两口钻井, 今 地温梯度均为 $3.61^{\circ} \mathrm{C} / 100 \mathrm{~m}$. 样品埋深 $945 \sim 4107 \mathrm{~m}$, 相对应的时代为 $\mathrm{E}_{3}^{3}-\mathrm{Q}$. 样品均为泥 岩, 元素分析的结果表明有机质类型为 $\mathrm{II}_{2}-\mathrm{III}$ 型. 样品根据石油工业部 1986 年的部颁标准进 行干酪根的分离和富集; 得到的干酪根样品一部分进行电子顺磁共振分析, 测定其自由基浓 度 $\left(N_{\mathrm{g}}\right)$; 另一部分进行光学分析以测定其镜质体反射率值 $\left(R_{\mathrm{o}}\right)$, 所测试样品之 $R_{\mathrm{o}}$ 均小于 $1.0 \%$.

\section{3 结果和讨论}

国外学者的研究表明, 在 $R_{\mathrm{o}}<2 \%$ 的时候, $N_{\mathrm{g}}$ 随有机质热演化程度的增加而增大, 在

1994-10-05 收稿, 1995-01-05 收修改稿

*国家“八五”重点科技攻关资助项目 


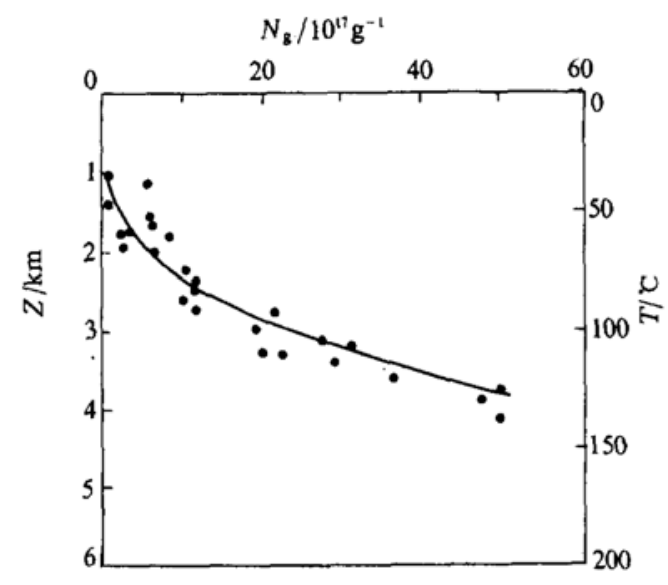

图 1 干酪根自由基浓度 $\left(N_{\mathrm{g}}\right)$ 与样品埋深、温 度的关系

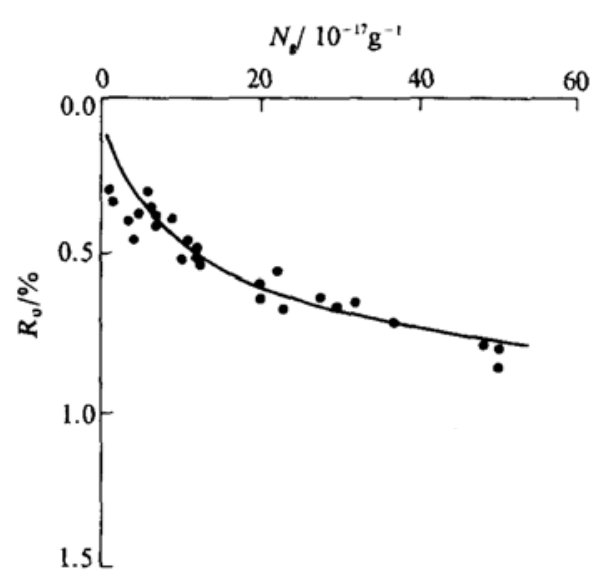

图 2 干酪根样品的成熟度与自由基浓度的 关系图

$R_{\mathrm{o}}=2 \%$ 左右 $N_{\mathrm{g}}$ 达到最大值, 随后减小 ${ }^{[1,2]}$. 我们对所研究的干酪根的 EPR 分析可见, $N_{\mathrm{g}}$ 与 有机质成熟度、埋深 (温度) 之间有良好的对应关系, 而且由于所研究盆地的快速沉积和沉降 环境, 可认为今地温即为样品所经历的最高温度.

(1) 随埋藏深度 (温度) 的加大, 自由基浓度逐渐增大; 在所研究样品的成熟度范围内 $\left(R_{\mathrm{o}}<1.0 \%\right), N_{\mathrm{g}}$ 与埋深 $(Z)$ 及今地温 $(T)$ 有很好的线性关系 (图 1):

$$
\begin{array}{ll}
Z=1130.82\left(N_{\mathrm{g}} \times 10^{-17}\right)^{0.3092}, & r=0.93(n=26) ; \\
T=54.6866\left(N_{\mathrm{g}} \times 10^{-1}\right)^{0.2994}, & r=0.91(n=26) .
\end{array}
$$

(2) 随样品成熟度 $\left(R_{\mathrm{o}} \%\right)$ 的增高, $N_{\mathrm{g}}$ 逐渐增大 (图 2). 我们根据实验数据对 $N_{\mathrm{g}}$ 与 $R_{\mathrm{o}}$ 进 行回归分析, 得到了 $N_{\mathrm{g}}$ 与 $R_{\mathrm{o}}$ 之间良好的线性关系. 因此, $N_{\mathrm{g}}$ 可作为有机质成熟度的指标. 对于本区的 $\mathrm{II}_{2}-\mathrm{III}$ 型干酪根, $N_{\mathrm{g}}$ 与 $R_{\mathrm{o}}$ 的对应关系为:

$$
R_{\mathrm{o}}=0.1357 \ln \left(N_{\mathrm{g}} \times 10^{-17}\right)+0.2040, r=0.87(n=26) \text {. }
$$

(3) 根据自由基浓度反演盆地的热历史. Pusey 是最早用 EPR 技术研究沉积盆地古地 温的人, 他用现代沉积盆地中实测的井温建立了 $N_{\mathrm{g}}$ 与最大温度的关系 ${ }^{\left[{ }^{3]}\right.}$. 由此我们可以引申 到更老盆地的研究, 即将未知热历史的样品的 EPR 参数与已知古地温的 EPR 参数的标准曲

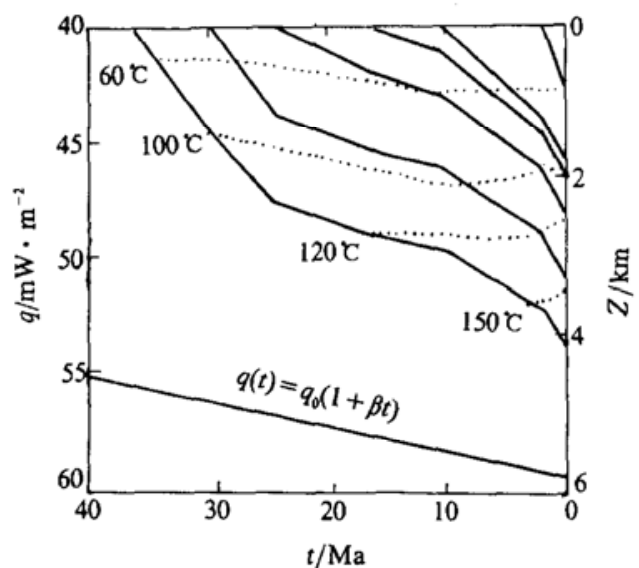

图 3 研究井的埋藏史和热流变化图 线图进行对比, 以期获得古地温. 此外, Bakr 等 认为用 $N_{\mathrm{g}}$ 与埋深关系之回归曲线的斜率也可推 算盆地的古地温梯度 ${ }^{[4]}$.

但是, 自由基浓度不仅与温度有关, 还与样品 在该温度下所经历的时间有关, 是温度和时间的 函数. 因此, 要详细研究盆地的热历史, 必须重建 盆地的构造、沉积埋藏史, 结合所得到的 EPR 参 数进行反演. 反演的方法是通过重建沉积埋藏史 和假设一个热历史模型, 计算沉积盆地有机质受 热过程,再用实测的有机质自由基浓度验证计算 结果, 通过反复修改热历史模式, 使计算的 $N_{\mathrm{g}}$ 和 
实测的 $N_{8}$ 一致或最大程度地吻合.

由于选取的样品最老年龄为 $34.5 \mathrm{Ma}$, 故假设热流变化为线性模型 - $q(t)=q_{0}(1+\beta t)$. 其中 $q_{0}$ 为实测今热流值 $59.42 \mathrm{~mW} / \mathrm{m}^{2}$. 根据研究井实测的 $N_{\mathrm{g}}$ 值, 我们用上述拟合计算方法 得到的 $\beta$ 值为: $\beta=-1.54 \times 10^{-3}$. 这样, 初步得出古热流为 (图 3):

$$
q(t)=q_{0}\left(1-1.54 \times 10^{-3} t\right) \text {. }
$$

同时, 我们用相应样品的实测 $R_{0}$ 值进行古热流的反演计算, 所得到热流因子 $\beta^{\prime}=-2.20 \times 10^{-3}$, 二者吻合得很好. 此外, $q(t)$ 随时间的增加缓慢减小的结论与用化学动力学方法算出的结果 相符.

总之, 利用 EPR 方法研究有机质的成熟度是可行的, 其自由基浓度 $\left(N_{\mathrm{g}}\right)$ 是有机质成熟度 的有效指标. 由于 $N_{\mathrm{g}}$ 与干酪根类型有关, 因此, 用 EPR 方法研究有机质成熟度要求有机质 的沉积类型要保持近似的稳定, 而且有机质尚未达到后成岩作用阶段 (即 $R_{0}<2 \%$ ). 在干酪根 的电子顺磁共振研究中, 干酪根的分离和提纯对实验的结果有很大的影响. 此外, 由于不同 的有机溶剂对有机质抽提能力不一样, 用不同的有机溶剂抽提后的干酪根其 EPR 参数有所不 同 ${ }^{[4, S}$. 事实上,被抽提出来的有机分子并无 EPR 信号, 只是它们的存在影响了自由基的相互 作用, 使 EPR 谱有所不同. 为了真实地研究有机质的自由基行为, 从而达到研究有机热演化 的目的, 本次实验未对干酪根样品中的可溶有机质进行氯仿清洗.

盆地古地温的研究是寻找工业油气藏、评价油气远景的重要依据; 盆地的动态演化研 究、油气成藏模拟及油气成藏的动力学研究都离不开古地温资料. 本文利用电子顺磁共振方 法所得到的单井 $q(t)$ 虽然不能完全代表整个盆地的古热流变化而应有更多的 EPR 资料来进 行评价,但利用自由基浓度拟合计算古地温毕竟是一种新的探索. 本文仅对 $\mathrm{II}_{2}-\mathrm{III}$ 型有机 质、高地温梯度的年轻盆地进行研究, 今后有可能通过更多盆地、更多类型有机质的研究来进 一步丰富和完善该方法.

\section{参考 文 献}

1 Durand B, Marchand A, Amiell $J$ et al. Étude de kerogenes par resonance paramagnetique electronique. In: Campos R, Goni J eds. Advances in Organic Geochemistr y, 1975, 1977. 753 779

2 Mrozowski S. ESR studies of carbonization and calification processes, Part I. carbonceous compounds. Carbon, 1988, 26(4): $521 \sim 529$

3 Pusey W C. The ESR kerogen method: a new technique of estimating the organic maturity of sedimentary rocks. Petroleum Times, 1973, 77: 21 26

4 Bakr M Y, Akiyama M, Sanada Y et al. Radical concentration of kerogen as a maturation parameter. Org Geochem, 1988, 12(1): 29 32

5 Petrakis L, Grandy D W. Anelectron Spin resonance spectrometric investigation of natural, extracted and thermally altered kerogenous materials. Geochimica et Cosmochimica Acta, 1990, 44(5): 763 768 